ARID International Journal of Educational and Psychological Sciences (AIJEPS) VOL: 3, NO. 5, January 2022

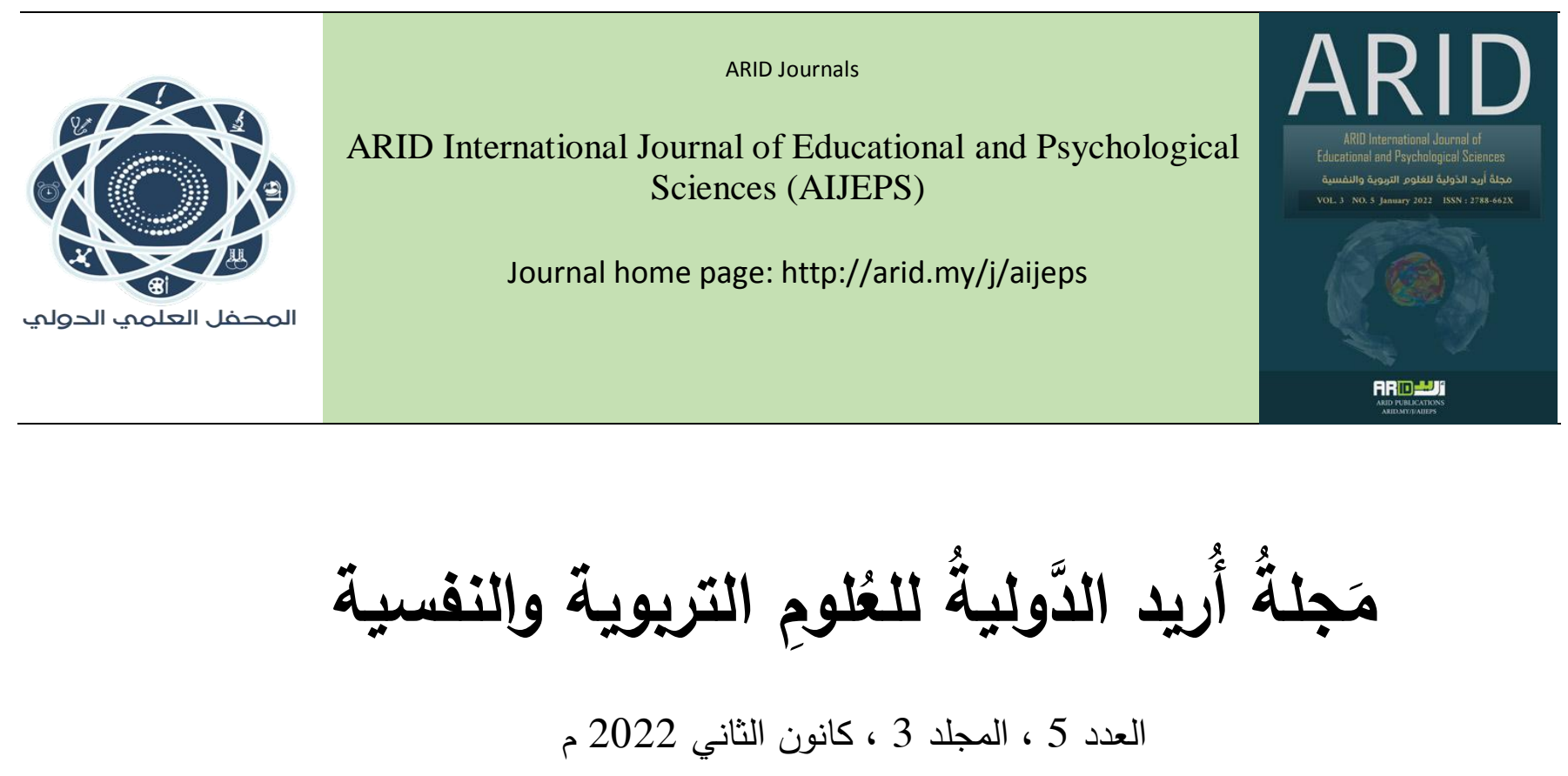

\title{
Factors for acquiring writing and ways of learning and teaching its skills (handwriting, dictation and written expression)
}
عوامل اكتساب الكتابة وطرق تعلمها وتدريس مهاراتها (الخط والإملاء والتعبير الكتابي) يمينة عطال$$
\text { وفاء بلخيري }
$$
كلية العلوم الإنسانية و الاجتماعية - جامعة الحاج لخضر - باتتة 1-الجزائر




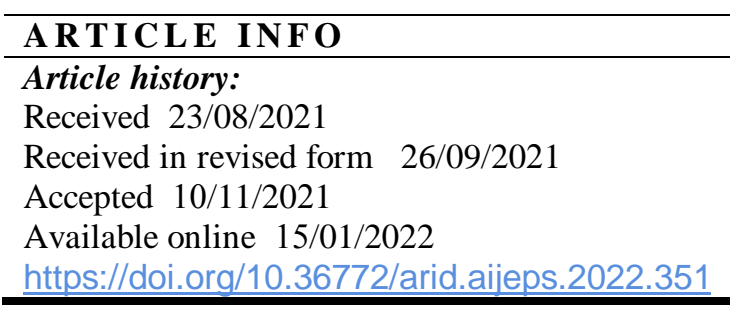

\begin{abstract}
Writing is the pride of the human mind throughout its long history, as it is a symbol of its humanity and the title of its civilization and its memory and its history. Writing is one of the means of communication by which a person can express his thoughts and feelings, and records what he would like to record of incidents, facts and information, in order to preserve them from oblivion and disappearance.

We will address in this research paper writing in two main axes; The first is an introduction to writing, the factors helping to acquire it, the stages of its learning, and methods of teaching it. As for the second axis, we will dedicate it to writing skills, each skill separately. handwriting, spelling and written expression, in terms of definition and teaching methods, as well as weaknesses in some of them and the reasons for that.
\end{abstract}

Key words : Factors of acquisition of writing - writing skills - handwriting - dictation - written expression 


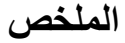

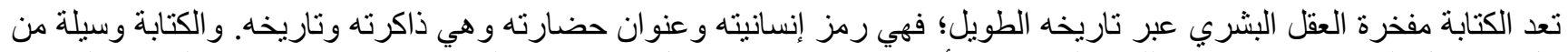

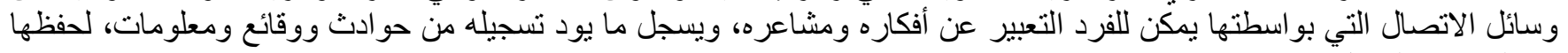

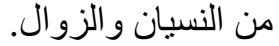

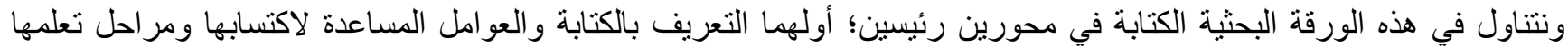

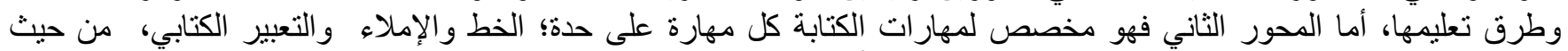
التعريف وطرق نعائه التدريس, وكذا مظاهر الضعف في بعضها و أسباب ذلك.

$$
\text { الكلمات المفتاحية: عو امل اكتساب الكتابة ـ مهار ات الكتابة ـ الخط ـ الإملاء ـ التعبير الكتابي. }
$$


للكتابة شأن عظيم ومكانة عالية ورفيعة؛ فهي الحافظة للتـاريخ و التراث الحضـاري، و إذا كانت القر اءة إحدى نو افذ المعرفة و أداتها، فالكتابة هي أعظم ما أنتجه العقل البشري، ويذهب الأنثروبولوجيون إلى القول بأن الإنسان بدأ تاريخه الحقيقي باختر اعه الكتابة. و هي من أهم أدوات التواصل في العصر الحديث، فمن خلالها ندون مذكر اتتا، ومخططاتنا، ورسائلنا وبحوثنا، وحساباتتا ومو اعيدنا، وشهادات ميلادنا ووثائقنا الرسمية. كما أنها الأداة الرئيسة في التعليم و التعلم؛ لذا تأخذ مكانًا مهرًا في مر اكز التعليم بمر احله المختلفة، بل إن أهميـة الكتابـة تزداد بعد تخرجنا من مر اكز التعليم إلى الحياة المهنية، وهنا يظهر مدى اكتسابنا وتمكننا من مهار اتها المختلفة. و إذا كانت اللغة تؤدي وظيفتين مهمتين في حياة الإنسان, و هما الاتصال وتسـيل عملية التفكير والتعبير عن النفس, فإن الكتابة قادرة عن أداء هاتين الوظيفتين وتزيد، وبالرغم من أنه ينظر إليها في المداخل الحديثة لتعليم اللغة باعتبار ها الفن الرابع، إلا أنها لا بد أن تكون سابقة الوجود للقر اءة، فنحن نقر أ ما هو مكتوب، وفي الوقت نفسه فلا يمكن للإنسـان في لغـة مـا أن يكتب كلمـة دون أن يكون قد قر أها أو رآها. و مهار ات الكتابة من خطو إملاء وتعبير كتابي، تعتبر من المهارات اللغوية الضرورية التي تحدد النجاح في الأداء المدرسي، وهي من أهم مقومات المناهج التربوية، فهي ضرورية لتعليم وتعلم كل المواد الأخرى، والمعلم يركز عليها في تقييم مسنوى تطور ونمو القدرات اللغويـة و المعرفيـة لتلاميذه، فالتلميذ الذي يعـاني ضـفا في مهار ات الكتابـة، قد يعاني أيضـا ضـعفا في التحصيل الدراسي.-Abdul .(Khafaji, 2021)

\section{مشكلة البحث:}

الكتابة كمادة تعليمية تندو للمتعلم أول مرة أنها عبارة عن رسم وتخطيط حروف بأثكال مختلفة واتجاهـات عديدة، لكن في حقيقة الأمر فخط هذه الرسوم أو الأشكال ليس بالأمر السهل، فهو يحتاج إلى مهار ات أخرى يجب أن يكتسبها ويتحكم فيها، أبسطها سلامة الحواس، و أعقدها - في سن مبكرة - إدر الك اليمين و اليسار ؛ لذا قد يستغرق تعليم كتابة الحروف الأبجديـة شـهورًا تسبقها تعلم طريقة خط الخطوط المستقيمة و المنحنية و المنكسرة و المتعرجة، ناهيك عن تعلم مفاهيم فوق وتحت ويمين ويسار ؛ حتى يدرك الطفل أين يضع النقطة وكيف يكون اتجاه الحرف.

ومما يزيد من تعقيد تعلم هذه المهارة هو احتو ائها على العديد من المهارات الفرعيـة التي اختلف بعض الباحثين في تحديدها, إلا أن أغلبهم يتفقون على تحديدها في ثلاث مهار ات رئيسة هي الخط, والإمـلاء, و التعبير الكتابي، تتدرج تحتها مهار ات فرعية عديدة، وكل 
مهارة قد تتطلب سنين لإتقانها، فمهارة الإملاء مثلا تندرج تحتها العديد من المهار ات, منها حسن كتابة التاء المفتوحة والمربوطة, وكتابـة الهمزة في مو اضـع مختلفة, و هذه المهار ات قد تستغرق المرحلـة الابتدائية بأكملهـا وقد لا يتقنها بعض التلاميذ مـع دخولهم المرحلـة المتوسطة وحتى الثانوية.

لذا جاءت هذه الورقة البحثية لتسليط الضوء على أهم العو امل و الثروط اللازمة لتعلم الكتابة, و أهم الأهداف وطرق التدريس المستخدمة في تعليم مهار اتها الثناث الخط والإملاء و التعبير الكتابي. أهمية البحث:

يستمد هذا البحث أهميته من الموضوع الذي يتناوله, و هو عوامل اكتساب الكتابة ومهار اتها وطرق تدريسها ، فهو استخلاص واستتباط من أهم الأبحاث والمؤلفات العربية والأجنبيـة حول طرق تدريس مهار ات اللغـة عامـة والكتابـة خاصـة، ويجد فيه المهتم بمجال طرق تدريس اللغـة العربية واضطر ابات اللغـة وصعوبات التعلم، كل مـا يههـه حول هذه المهارة الضرورية و الأساسية للتعليم و التعلم؛ لفهم خصائصـهاو وعو املهـا ومكوناتهـا؛ وذلك مـن أجل اختيـار الأسـلوب التعليمسي المناسـب للمتعلم، أو الطريقـة العلاجيـة المو افقـة لقدرات المتأخرين أو المضطربين لغويًا. وسوف نتناول في هذه الورقة عوامل اكتساب هذه القدرة الإنسانية ومهار اتها في محورين رئيسين؛ أولها التعريف بالكتابة والعوامل المساعدة لاكتسابها ومر احل تعلمها وطرق تعليمها، أما المحور الثاني فسوف نخصصـه لمهار ات الكتابـة كل مهارة على حدة؛ مهار ات الخط ومهار ات الإملاء و أخيرا مهار ات التعبير الكتابي, من حيث التعريف, و الأهداف, والأسس, وطرق التدريس, وقائمسة المهارات, وبعض الضعف في هذه المهار ات و أسبابه.

أولًا. مفهوم الكتابة:

قال الله تعالى: "ن و القلم وما يسطرون". (القلم، 1).

وقال تعالى: "اقر أوربك الأكرم. الذي علم بالقلم. علم الإنسان ما لم يعلم". (العلق، (3- 5).

تعريفها لغة واصطلاحا:

تعرف الكتابة لغة على أنها الجمع و الثد، و التنظيم، كما تعني القضاء و الالتزام و الإيجاب. (الخويسكي، 2005، 164). أما اصطلاحا، فهناك من اقتصر على تعريفها بالحروف والرسوم الخطية التي تترجم اللفظ، وهناك من اعتبر هـا أداة للتعبير عن 
ويعرفها قاموس الأرطوفونيا بأنها: "تمثيل للفكر واللغة عن طريق وحدات خطية، خاصة بمجتمع لساني معين". Frederique et ( al, 1997, p : 66 ويعرفها فتحي يونس بأنها: "عملية ذات خطو ات متتالية يتبع بعضها بعضًا، وتتر ابط في حزمة واحدة, يبدأ بعضها قبل عملية الكتابة نفسها"، ويعني هذا أن قطعة الكتابة سو اء قطعة تعبير تقدم لمدرس اللغة، أو قصة قصيرة، لا يمكن أن تتصف بالكمال، أي أنها يمكن أن تكون موضعا للمر اجعة والتنقيح عدة مرات. (عبد الباري، 2010، ص : 78). و هناك تتوع كبير في التعريفات التي تتاولت الكتابة، و هذا راجع إلى طبيعة هذا المفهوم المعقد و المتشابك من جهة، ومن جهة أخرى لتعدد التخصصات العلمية التي تتاولتها من أدب ولغة إلى لسـانيات وعلم النفس و علوم التربية، فكل تخصص يعرفها حسب ما يخدم موضو عه و أغر اضده.

\section{ثانيا ـ الثروطو العوامل المساعدة على تعلم الكتابة:}

إن الطفل لا يكتسب لغته المكتوبة ويتقن مهار اتها بالطريقة نفسها التي يكتسب بها لغته الثشوية، فاكتساب اللغة المكتوبة قراءة وكتابة، يجب أن يخضع لعملية تعليم مقصودة ومنظمة، و لا بد أن تتوفر شروط جسمية ونفسية للى المتعلم، بالإضـافة إلى عوامل مسـاعدة من استقر ار نفسي واجتماعي و غير ها من العو امل التي نتطرق إليها فيما يلي:

\section{1.}

إن الكتابة عبارة عن نشاط حركي معقد ومميز ينمو بصعوبة؛ حيث إنه يتطلب التحكم في عضلات اليد والتآزر الحركي و العصبي العضلي لحركة الأصابع وحركة العينين، وما يتطلبه الأمر من سرعة ودقة. (الناثف، 1998، ص : 100).

وكثف الفيزيولوجيون عبر دراساتهم التشريحية للفعل الخطي، أن الكتابة عملية حركية بالدرجة الأولى، يتم أداؤها عن طريق القيام بعمليات حركية و عصبية وتمثيلية في منتهى التعقيد والحساسية، ويتوقف النشاط الحركي على نضـج الجهاز العصبي العام، والأعصساب الحسية الحركية، والانسجام العضلي للحساسية الحركية لعضلات اليد، ومن المؤكد أن الفعل الخطي يتبع سيرورة عصبية وظيفية دقيقة نجمل خطو اتها في ثـلاث مر احل متسلسلة ومتعاقبـة ومتكاملـة وهي: التحكم الفيزيولوجي العصبي، التحكم العصبي، الضبط الحركي. (جعري، 2003، ص : 50 - 51). 


\section{2. نمو الصورة الجسمية:}

يقول شونتال تولون لكي يدمج الطفل مختلف عناصر الكتابة، ويفهم كيف يأخذ الخط مكانه في الورقة، يجب أن يكون لديهه وعي جيد لصورته الجسمية، وحسب بول شلايدر فالصورة الجسمية هي الصورة ثلاثيـة الأبعاد التي يملكها كل شخص عن نفسـه، وبالنسبة لبولش فيعرفها بأنها المعرفة الآنية المباشرة التي نمتلكها عن جسمنا في حالة الثبات أو الحركة، والعلاقة بين مختلف الأعضـاء فيما بينها وخاصة في علاقتها بالفضاء والأشياء المحيطة بنا. (Toulon-Page, 2001, p : (T) ).

\section{3. التوجه في الفضاء.}

إن هذا الجســ يجـب أيضـا أن يـرك في علاقاتهـ بـالمحيط وكيف ينتقل بشـكل سـلس في فضـاء مـنظم، ويكتشـف بشكل سـليم معرفة الأعلى، الأسفل، اليمين، اليسار، المستقيم و المنحني، الكبير و الصغير، الداخل و الخارج، و المسافات بين الأشياء، ويتعلم أن يتقدم ويرجع إلى الوراء، والدوران حول نفسـه، والقفز و الزحف تحت الأشياء، ويجب عليه أن يتلفظ بما يرى ومـا يحس ومـا يلاحظه على الآخرين عند القيام بعمل ما. (Toulon- Page, 2001, p : 33) إن امتلاك المفاهيم الإدر اكية المكانية: (الور اء، والأيسام، واليمين و اليسـار ، وفوق وتحت...) وتحديد اتجاهاتها في الفضـاء الواسع يمكن المتعلم من التوجه المحكم في فضاء الورقة الضيق، ورسم الرموز الخطية فوق خطوطها بإحكام و أطو ال متناسبة مع بنيـة الحروف سو اء أكان مستقلا بذاته عن بنية الكلمة أم بداخلها. (جعفري، 2003، ص : 53). ونمو القدرة على الإدر الك المكاني لا يمكن تحقيقه بعيدًا عن التعلم و التدريب, كمـا أنه لا يمكن تصور ها بعيدا عن النمو الحسي و العقلي لشخصية المتعلم، و لا يمكن الفصل بينهما في العملية النهائية.

$$
\text { 4. القدرة على الإدراك الزماني. }
$$

يعرف نوربار سيلامي مفهوم الزمان، بأنه : "فترة، تتميز بتسلسل أحداث وتغير وضـ، وهو تركيب ذهني يهدف إلى التحكم في الزائل". (Sillamy, 1989, p : 237).

و من المهم جدًا لكي تكتسب الكتابة إيقاعا شخصيا وسهلا، أن تكون المفاهيم الزمانية مدركة جيدا لدى الطفل، فالماضي و الحاضر و المستقبل في تتابع دون انقطاع ودون نهاية، فهي منل الكتابة في انسيابها، فكل حرف يتبع لاحقه دون إخـلال في التنظيح, ومن المهم أن يكون لدى الطفل تمثيل عقلي جيد للكلمات المفردة مثل: البارحة، اليوم، غدًا، بعد غد، صباح، مساء ويفهم جيدًا التتابع المنطقي للأحداث في قصة ما، أو مختلف مر احل حدث ما. ( Toulon Page, 2001, p : 33). 
وفي الواقع، لا يمكن فصل مفاهيم التوجه الفضائي والزمان لهذا نجدها في أغلب المراجع تحت مصطلح واحد هو التنظيم المكاني الزماني, فالزمان و المكان مفهومان مرتبطان و متداخلان, وباكتساب مفاهيم المكان يمكن اكتساب مفاهيم الزمان.

و الكتابة باعتبار ها نشاطًا حركيًا فهي أيضا نشاط مكاني - زماني بـالغ التعقيد؛ فالطفل لكي يكتسب ويتعلم الكتابة بشكل جيد يجب عليه أن يكتب رموزا موجهة بطريقة صحيحة وموضو عة في مكانها الصحيح، ويحترم قو انين الترتيب والتسلسل التي تجعل من تلك الرموز كلمات وجمل لها معنى ومدلول، ولا يتم هذا إلّا باكتسابه وتمكنه من المفاهيم المكانية و الزمانية.

وقد بين العديد من الدر اسات في مجال صعوبات التعلم الأكاديمية خاصة، أن نسبة مرتفعة من المضطربين كتابيا لديهم بنية مكانية وزمانية سيئة.

بالإضافة إلى هذه المفاهيم الثناثثة (الصورة الجسمية، مفاهيم المكان و الزمـان) التي تعد من عناصر النمو النفسيـ الحركي ومن الشروط الأساسية لاكتساب اللغة سواء الثفوية أو المكتوبة, هناك أيضًا مفهوم لـه أهمية كبرى بالنسبة للنمو النفسيـ الحركي واكتسـاب وتعلم الكتابة خاصة وهو استقرار الجانبية.

\section{5. الجانبية واليد المفضلة في الكتابة.}

يعرف سيلامي الجانبية بأنها: "سيطرة حسية وحركية لجانب من جسم الإنسـان على الجانب الآخر ؛ من أجل تنظيم ثابت للفضـاء المحيط، تتجلى من خلال تفضيل الفرد لاستعمال طرف دون الآخر أو عين دون الأخرى من أجل القيام بعدل يتطلب التركيز والدقة. .(Sillamy, 1996, pp :100-110)

إن تفضيل الطفل لاستخدام يد أو عين أو رجل معينة، تحكمه عدة شروط منها: الخصـائص العصبية و الجينية، والظروف المحيطة من تنشئة اجتماعية وتعلم وتدريب.

ويجب على الطفل أن يدرك يمينه ويساره ويعرف جانبيته، فهو يبقى مدة طويلة (من الميلاد) يستخدم جانبيه معًا دون انتظام قبل أن

يختار استعمال اليمين أو اليسار، وهذا يتم في حدود سن السابعة. (Toulon, Page, 2001, p : 33 ).

ونجد أن معظم الأطفال يستعملون اليمين (حوالي $90 \%$ \%)، أمـا البقية (10 \%) فيستعملون البسار ، إلا أن هناك من الأطفال من لا

تتكون لديهم الجانبية خلال هذه السن حيث يستمر ذلك إلى غاية (07-06) سنوات حتى يتوجهون إلى استعمال اليمين, أمسا البقية الأخرى فيظهرون سوء تتظيم الجانبية، ويتجلى ذلك من خلال صسوبة القيام بالحركات الدقيقة واضطر ابات الكتابة التي ترجع إلى اضطر ابات الحركة الخطية. (تغليت، 2008، ص : 122). 
و الكتابة باليد اليسرى مشكلة ملحوظة بين عدد من التلاميذ, وأخذ هذه المشكلة باهتمـام ملفت للنظر أمر لا مبرر لله، والكثير من المعلمين عندما يلاحظون تلاميذ يكتبون بيدهم اليسرى يحاولون تغيير كتابتهم من اليد اليسرى إلى اليد اليمنى، وبالنسبة إلى عدد كبير من هؤلاء الأطفال ممن تثبت كتابتهم باليد اليسرى, يصبح من الصعب تعليمهم الكتابة باليد اليمنى. (الحسن، 2005، ص : 108). وبينت الدر اسات أن الطفل الذي يبدأ باستخدام اليد اليسرى في الكتابة يجب أن يمرن على استخدام اليد اليسرى و لا يدفع للكتابـة باليد اليمنى، أما بالنسبة للأطفال الذين يأتون إلى المدرسة ويغلب عليهم التنارجح بين اليد اليسرى و اليمنى فيشجعون على استخدام اليد اليمنى ما دام غالبية الناس يستخدمون هذه اليد في الكتابة. (الحسن، 2005، ص : 109).

\section{6. ستوى اللغة الثفوية.}

إن مستوى اللغة يتذخل في تعلم الكتابة؛ فاللغة المكتوبـة تتطلب مستوى عامًا من التطور على مستوى المفردات وسـهولة التعبير، و المشاكل الإملائية الملاحظة لدى الأطفال و الناتجـة عن عدم إدر اكهم السليم لبنيـة الكلمات كما لدى الر اثد، يؤدي إلى توقفات و إعادة كتابة وتردد في الفعل الخطي، وهذا ما يؤدي إلى اضطر اب مسار التخطيط، وكلما كان التحكم في اللغة ضعيفا فإن ترجمتها كتابيا يكون صعبا، وكما أن اللغة تترجم بشكل سهل التفكير فإن ترجمته الخطية تصبح آلية, وبهذا انسياب التفكير مباثرة على الورق. (Toulon .(Page, 2001, p : 36

أضف إلى هذا، إن النطق السليم لأصوات الحروف مستقلة بذاتها أو داخل بنية الكلمـات أو في المتصل من الجمل يكسب الطلاقة اللغوية، مما ييسر الترجمة الخطية للمنطوق وكذا حل مشكلات التحليل الخطي بحسب مـاتوصل إلبه "أجورياجير ا" و"أوزياس"، فقد أشثارت "أوزياس" أن اضطر ابات اللغـة الثفوية تؤدي إلى بروز أعر اض مشوهة للكتابـة تتمثل في: البطء في الكتابـة، خلط الحروف المتشابهة شكلا وقر اءة وكتابة، التوقف عند كل حرف من حروف الكلمة في الكتابة، بالإضافة إلى سوء تمييز الكلمات في الجمل وفصل حروف الكلمة الواحدة، والخربشة واختراق النظافة والوضوح. (جعفري، 2003، ص : 62 - 63). 7. نضج الجهاز العصبي وسلامة الحواس.

إن الكتابة هي نشاط حركي دقيق جد معقد، يكتسب بشكل صعب نو عا ما وفي مدة زمنية طويلة مقارنة بالكلام، وأصبح من المعلوم أن التطور النفسي الحركي للطفل هو دون شك الركيزة الأساسية لتعلم الكتابة، وهذا التطور النفسيـ الحركي لا يكون إلا بنمو وتطور الجهاز العصبي الذي يعتمد بدوره في نموه وتطوره على سلامة الحواس (السمع والبصر خاصة) والخبرة و التعليم والتدريب. 


\section{8. الأكاء والنمو العقلي:}

لقد جاءت العديد من النظريات لتبر هن على أن النمو اللغوي لا يكون وينطور دون قدر من النمو العقلي، بغض النظر عن أيهما أسبق أو أيهما أهم للآخر، فإدر الك الطفل لعلاقة الرمز و الإشـارة في الثكل المكتوب لا يتم دون تفكير وخبرة سابقة مع الرموز وقدرة على فهمهــا وتفسير ها، كمـا أن إدر الك الطفل للعلاقـات المكانيـة و إدر اك تتـابع الحروف وفهم العلاقـة بين أصـوات الكـلام و أنثكال الرمـوز المستخدمة في الكتابة، والقدرة على التصور، كلها عمليات عقلية لا يتمكن منها الطفل قبل بلوغه السادسة من العمر العقلي. (الناثف،

$$
\text { (101-100: 1996 ص ص (196) }
$$

و اتفق الباحثون أن امتلاك الكتابـة يقوم على نمو الفكر التمثيلي (أو المفاهيمي) (la pensée conceptuelle) الذي تتحدد معالمـه الأولى حسب بياجي وفالون مـا بين السادسـة والسـابعة، وتتطلب القدرة التمثيلية مستوى عـالٍ من الوعي و التفكير و المنطق, تسمح لها بتمثنيل أفكار الو اقع و أثيائه في مفاهيم رمزيـة خاصـة، وذلك بواسطة الوظيفة الرمزيـة التي تعمل على تخزين النمـاذج الحسية الغائبة, وتوجيهها بو اسطة المصورات الحركية وفق متطلبات الواقع المعيش. (جعفري، 2003، ص : 59). ور غم أن هناك عدم اتفاق بين نتائج الدراسات التي تناولت العلاقة بين مستوى الذكاء ومستوى الكتابـة، إلا أنها تتفق على أنه يجب أن يكون هنالك مسنوى عقلي يصل إلى ست سنوات كحد أدنى، لكي يسنطيع الطفل تعلم الكتابة والقر اءة.

لقد اختلف التربويون و علماء النفس في تحديد السن المناسبة لتعليم الطفل الكتابة، وكما سبق أن ذكرنا فالكتابة مهارة حركية في أول الأمر, فمن البديهي أن يكون الطفل قد وصل سنًا يستطيع فيها تحريك يديه وذر اعيه و أصابعه بشكل محكم ومتناسق وثابت؛ لكي يستطيع التحكم في شكل خطه.

و أقرت سيمون ت (TA. Simon) - بناء على النموذج الخطي المقدم لمائة طفل تثر اوح أعمار هم بين الثالثة و السادسة من العمر لتقليد رسمهــ مدى ضـرورة تعليم هذا النشـاط التعليمي في سن الخامسـة، ذلك أن الكتابـة حسب مـا توصلت إليهه هذه الباحثة تحكمها الخربشة في سن الثالثة، وتتميز سن الر ابعة برسم الأشكال المغلقة والمفتوحة دون القدرة على التمييز بين الدائرة و المربع، وفي سن الخامسة يستطيع الطفل تمثيل الأشكال (المربع، المستقيم، الدائرة، المثلث، المنحنى...) وترميز ها في قاموسه الذهني، وتتميز سن السادسة بقدرة الطفل على رسـ المعين والصـور المغلقـة والنجـاح في إنجـاز الاختبـار ات الثـكلية, وذلك لنمو القدرة الترميزيـة للخطوط لديـه. (جعري، 2003، ص 57-58). 
وخلص "بياجي" و "انهلدر" من التجارب المعروضة على الأطفال إلى أن سن السادسة تعد السن المناسبة لتعلم الكتابة، وذلك لقدرة الأطفال على تقليد الأشكال المعقدة ووعي العلاقة التي تربطها وتميز ها بدقة، مثل الزوايا و الأبعاد والاتجاهات. (جعفري، 2003، ص

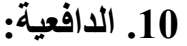

قد تتوفر كل الثروط التي أتينا على ذكر ها سابقا لاى الطفل، لكنا نجده لا يستطيع الكتابة ولا حتى رسم بعض الأشكال الهنسية، إن هذا يرجع إلى شرط مهم وأساسي أيضا في تعلم الكتابة وهو الدافعية والرغبة في الكتابة وتعلمها، فحتى يستطيع الطفل أن يتعلم يجب أن يكون لديه دافع حتى يقوم بالمحاولة في التعلم مثل حب الاستطلاع و الحافز لاكتساب الكفاءة، والحاجة إلى الثشعور بالنجاح، فالطفل مثلا قد يبدي حب استطلاع في عمل و الده، ويظهر رغبة في أن يقلده، فإذا شـاهده يكتب يحاول تقليده، وبالتالي ينولد لديه الدافع لتعلم الكتابة وممارستها، وكتابة المعلم أمام التلاميذ في رياض الأطفال أو أثناء تعليم المبتدئين القراءة والكتابة، يولد لديهم الدافعية لتعلم الكتابة تقليدا لمعلمه، فهو النموذج الذي يقلده الأطفال في المدرسة ويتمثلون به. (الحسن، 2005، ص : 127).

وخلاصـة القول, إن من العو امل الضرورية و الأساسية لتعلم واكتسـاب الكتابـة: النضـج العصبي وسلامة الحواس خاصـة السمع و البصر، و النمو النفسي الحركي السليم المنمثل في اكتساب الصورة الجسمية والتوجه في الفضـاء واكتساب مفاهيم المكان و الزمان، و واستقرار الجانيبة، بالإضافة إلى النضج الحركي بصفة عامة ونمو وتطور المهارات اليدوية بصفة خاصة. هذه الثروط التي تبدو تكوينية فيزيولوجية يمكن أن نضيف لها شروطا وعوامل أخرى عقلية ونفسية, متمنلة في قدر من النمو العقلي ومستوى من الذكاء والتذكر، واستقرار عاطفي ودافعية جيدة نحو تعلم الكتابة، هذه العوامل تسهم الأسرة والمدرسة بشكل كبير في توفير ها للطفل، وبالنظر إلى مجموع هذه العو امل و الثروط، يمكن القول أنه من الصعب تحديد سن واحد لتعليم الأطفال الكتابة؛ وذلك لاختلاف سن تو افر هذه الثروط من طفل لآخر؛ ففي حين يسنطيع طفل في الر ابعة كتابة بعض الحروف والأرقام، فلا يستطيع طفل آخر

$$
\text { ذلك إلا في سن السادسة أو السابعة. }
$$

يؤكد التربويون أن الطفل الصغير يظهر سلوكيات الكتابة المبكرة منذ سنوات حياته الأولى، حنى أصبح يستخدم في أدبيات الطفولة مصطلح "تفتح الكتابة" ليصف السلوكيات الأولية للأطفال في الكتابة التي تسبق عملية الكتابة الفعلية كما عند الراشد، وتنطور هذه السلوكيات لتصل إلى الكتابة المتعارف عليها، و هناك عدة تقسيمات لمر احل الكتابة نذكر منها تقسيم سولزباي وتقسيم آخر تقسم فيهـ مر احل اكتساب الكتابة حسب السن و الخط المنتج. 


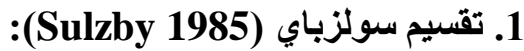

وقد صنفت سولزباي (Sulzby 1985)، كتابة الأطفال في مرحلة الطفولة المبكرة إلى ست فئات رئيسة وهي:

أ. الكتابة من خلال الرسم: وفيها يستخدم الطفل الرسم للإشارة إلى الكتابة، ويحاول الطفل إنجاح العلاقة بين الرسم و الكتابة دونما

إرباكهما، إذ يرى الطفل الرسم أو الكتابة كوسيلة اتصال لرسالة محددة وذات معنى، ويمكن للأطفال الذين يشاركون في الكتابة من خلال الرسم قراءة رسوماتهم, وكأنها تحمل كلمات مكتوبة، فلا يقصد بالرسم هنا رسم أثنكال منسقة ومنتظمة، و إنما رسم خطوط متقطعة، و غالبا ما تكون عثو ائية.

ب. الكتابة من خلال الخربشة: يخربش الطفل ظانا أنه يكتب، و غالبا ما ييدو وكأنه يكتب، ويخربش من اليمين إلى اليسار (اتجاه الكنابة في اللغة العربية) إذ يحرك الطفل قلمه كما يفعل الر اند،، وتحاكي خربشة الطفل هذه كتابة الر اثند. ج. الكتابة من خلال صنع أثكال مشابهة للحروف: تبدو الأشكال في كتابة الطفل لأول و هلة كالحروف, ومع ذلك تظهر الملاحظة القريبة أنها تبدو فقط مثل الأحرف، ولكنها ليست أحرفا، بل مجرد أثكال مختلفة.

د. الكتابة من خلال توليا وحدات ثم تعلمها مسبقا أو سلاسل الحروف: يستخدم الطفل السياقات المتعلمة من الأحرف من مصادر مختلفة مثل اسمه، ويغير أحيانا تسلسل الحروف، أو يكتب الأحرف نفسها بطر ائق مختلفة أو يولا أحرفا بالطريقة العشو ائية. هـ. الكتابة من خلال التهجئة المبتكرة: يظهر الأطفال مبدئيا العديد من المستويات للألفاظ المبتكرة، ويخلق الأطفال تهجئتهم الخاصة بالكلمات عندما لا يصلون للتهجئة المتبعة أو المتعارف عليها التي يظهر ها الراشدون، ففي اللفظ المبنكر الذي يختر عه الطفل، قد يمثل حرفًا ما أو مجمو عة من المقاطع, وأحيانـا لا تفصل بين الكلمة والكلمة مساحة معقولة، وكلمـا نضجت كتابة الطفل نشابهت كلماته مع الكتابة المتعارف عليها، وقد يضيف الطفل أو يلغي حرفا أو أكثر. و. الكتابة من خلال اللفظ المتعارف عليه: يكتب الطفل هنا بالطريقة المتعارف عليها، والتي تثبه كتابة الراشد. (أحميده، 2009،

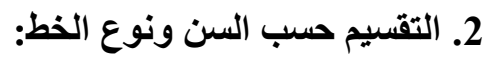

ويذهب كتاب آخرون إلى تقسيم مراحل اكتساب الكتابة حسب السن ونوع الخط المنتج، ومنهم عبد الرحمان مصطفى (1989)، والبجة (2002) كما يلي: 
أ ـ مرحلة السنة الأولى والثانية: (ويطلق عليها مرحلة ما قبل التخطيط): وهي مرحلة بطلق عليها اسم مرحلة الرسم التصـويري، أو الصور الآلية لكتابـة الطفل؛ حيث تعد فيها شخبطة الأطفال على الأبواب والجدران في المنازل المنطلق الأول لتعلمهم الكتابة؛ وذلك لكونهم يعبرون بها عن رغباتهم في إخر اج الصور العقلية إلى عالم الواقع في محاولة منهم لتفسير تللك الشخبطة للآخرين من حولهم. ب ـ مرحلة السنة الثالثة والرابعة: (ويطلق عليها مرحلة التخطيط التلقائي): يبدأ الطفل في بداية هذه المرحلة بالتخطيط غير المنتظم، وسبب ذلك إما أن الطفل يكون راغبا في محاكاة الكبار ، أو يأتي ذلك عن طريق الصدفة؛ حيث تكون التخطبطات في اتجاهـات متباينة تعبر عن بعض الأحاسيس العقلية والجسمية، ثم يتطور التخطبط التقليدي غير المنظم عند الطفل ليصبح منظمـا بغض النظر عن كون هذه الخطوط رأسية أو أفقية أو مائلة.

ويمكن أن يمنل تعبير الطفل في هذه المرحلة معنيين: رغبة الطفل في نقل خبرة ما للآخرين، أو بداية ظهور التعبير الرمزي للى الصغير ، وفي هذه المرحلة يصل الطفل إلى نوع من التو افق الحركي بين أعضاء الجسم واليد، كما تظهر تخطيطات مقيدة ومقصودة تتبع حركة اليد و أخرى متجانسة وتخطيطات أخرى غير متجانسة.

ج - مرحلة المحاكاة عن بعد (4 - 5 سنوات): في هذه المرحلة ينسخ الطفل نموذجـا لكلمـة مكتوبـة على مسافة بعيدة نوعا مـا، مثل الكلمة المكتوبة على السبورة، أو على بطاقة معلقة على الحائط، إلا أنه يتخلل هذا التقليد بعض الأخطاء، لأنه يتطلب انتقال نظر الطفل من و إلى النموذج المكتوب، وهي مهارة أساسية في تعلم القراءة والكتابـة، كما يتطلب مجهودا لتحليل عناصر اللفظ المكتوب ونسخ الصور المعلقة لكل عنصر من عناصر اللفظ المكتوبة مع المحافظة على ترتيب كل العناصر.

د ـ الكتابة في المدرسـة (5 - 7 سنوات) تبدأ هذه المرحلة مع دخول الأطفال المدارس، والتحاقهم بالصف الأول، ويفترض أن يكون الطفل قد أنهى المر احل السابقة، وقد أصبح على قدر من النضج العقلي والجسمي، ومـع هذا فإن علمـاء التربيـة ينصـون دائمـا أن تخصص مدة لا تقل عن ثلاثة أسابيع كفترة للتهيئة. (الأسطل، 2010، ص : 48 - 49). إذن يتفق الدارسون لتعليم الكتابة للأطفال أن بدايات الكتابة عند الطفل تكون في السنة الأولى إلى الثانية من العمر، عندما يبدأ الطفل في الخربشة على الجدران و الأبواب، ثم يكتسب الطفل تدريجيا القدرة على تخطيط أشكال منظمـة ومفهومـة، ومنها بستطيع تعلم خط الحروف و الأرقام و الكلمات.

ويؤدي المحيط الذي يعيش فيه الطفل دورا رئيسًا في ظهور هذه المحاو لات الأولى للكتابة وتطوير ها، خاصة منها المستوى الثقافي و الاقتصـادي للأسـرة، فالطفل الذي يعيش في أسرة يكون فيها الأب و الأم متعلمين و الإخـوة كذلك فهو دائمسا يشـاهدهم إمـا يقرؤون أو يكتبون، وبهذا يحاول تقليدهم باعتباره سلوكا مقبو لا لدى هؤلاء الكبار. 
كمـا أن تـوفر الأقـلام وأقـلام التلـوين والكـراريس والأوراق و القصـص المصـورة المخصصــة للتلـوين والكتابـة للأطفـال الصـغار، و الالتحاق بالروضة، تجعل الطفل بهتم بنشاط الكتابة ومستعدا له، أكثر من طفل محروم من هذه الإمكانيات والظروف.

\section{رابعا - طرق تعليم الكتابة.}

على الرغم من أن الطفل يحاول في بداية سنو اته الأولى قبل دخوله المدرسة أن يكتب ويخط، إلا أن كل تخطيطاته تكون بعيدة عن الكتابة المتعارف عليها لدى الر اثدين، لذا يجب أن يخضع لتعليم وتدريب مقصود ومنظم، و هذا يتم في الغالب إمـا في الروضـة، أو حتى دخوله المدرسة، وقد ذكر المتمون بهذا المجال العديد من المر احل و الطرق لتعليم الكتابة للأطفال نذكر منها نثلاث طرق معروفة لدى التربويين و هي طريقة مر احل الكتابة، والطريقة التحليلية و الطريقة التركيبية. 1. طريقة مراحل الكتابة: فنجد رجب فضل الله يذكر ثلاث مراحل لتعليم الكتابة للأطفال وهي: أ ـ مرحلة التمهيد:

و المطلوب في هذه المرحلة تدريب الأطفال على التحكم الحركي عن طريق أنشطة الرسم و التخطبط في منضدة الرمل و التمرينات الرياضية لليدين و الكفين والأصابع، و ألعاب الفك و التركيب و البناء، و الكتابة في الهواء ورسم الخطوط بالطباثنير ورسم الدو ائر ووضـع النقاط على الخطوط المرسومة وعمل الأشكال باستخدام الصلصسال، واللعب بنشـارة الخشب ولصق الصور وتجميع الأشكال، و هذه كلها أنشطة يقوم بها الأطفال من خلال ألعاب لغوية تسهم في النضج العضلي العصبي.

\section{ب ـ مرحلة تعليم الكتابة:}

وفيها يبدأ الطفل - وبعد أن يكون قد نطق بالجمل والكلمات المرسومة، وثم تجريد هذه الجمل أو الكلمات إلى حروف ـ في تعلم كتابة الحرف المشتق من كلمة لها معنى لديه, و الكلمة مأخوذة من جملة قر أها وفهم معناها. وتعليم الكتابة بهذا الشكل يستمد من استخدام الطريقة التحليلية في القراءة، ويتم باستخدام الطريقة التركييـة، وهذا هو الثكل الأكثر شيو عا، حيث يركز الطفل على رسم الحرف بكل مكوناته، مميزا بين شكله في أول الكلمة، وفي وسطها وفي آخر هـا، ويفرق بينه وبين الحروف المنقاربـة معـه في الثكل، ويحتاج الطفل في هذه المرحلـة إلى التدرج والتدريب المستمر، بالصبر في تعليمهه حتى يستغرق الحروف جميعها وفي جميع أوضـاعها، كمـا يجب التركيز على الكتابـة المشبكة (المتصـلة) حتى يعتادهـا الأطفـال، ويجدون فرصـا لاستخدامها في حياتهم. 
وفي هذه المرحلة تتكون لاى الأطفال عادات الكتابة, من ثم ينبغي الاهتمام بإمساك القلم بشكل صحيح، ووضع الورقة بأسلوب مريح، والجلسة الصحيحة أثناء الكتابة، كما أن هذه المرحلة فرصة لغرس بعض العادات السليمة المنصلة بالنظام والنظافة والدقة.

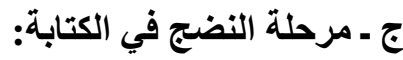

وفي هذه المرحلة يبدأ تدريس الكتابة بالثكل المعروف في العمل المدرسي: إملاء، خط، تعبير نحريري، ويهدف تعليم كل فرع منها إلى تتمية المهار ات الكتابية المنصلة به.

على الرغم من أن رجب فضل الله قد فصل في هذه المر احل وما يجب أن ينعلمه الطفل، إلا أنه لم يحدد لنا المدة الزمنبة التي تتطلبها كل مرحلة، أي كم من الوقت يجب أن يتدرب الطفل في المرحلة الأولى حتى يستطيع الانتقال إلى المرحلة التالية. (فضل اله، 1998،

و هناك طرق عديدة أيضا ذكرت في الأدب التربوي حول طرق تعلم الكتابة نذكر منها طريقتنين مشهورتين هي الطريقة التحليلية

$$
\text { للمربي (دكرولي)، و الطريقة التركيبية لـ (منتسوري). }
$$

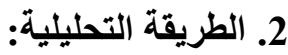

ونادى بهذه الطريقة المربي (دكرولي) وتعتمد هذه الطريقة على ربط الكلمات المكتوبة بالأشياء المحسوسة لهذه الكلمات، ويمر تعلم

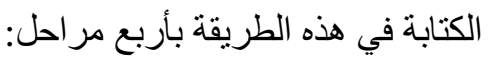

المرحلة الأولى: يلقي المعلم على التلاميذ بعض الأوامر المتصلة بأثنياء محسوسة من مدركاتهم، مثل: ضع تفاحة في الطبق، فينفذها الأطفال ثم تكتب هذه الأوامر على لوحة خاصة بخط كبير وتعلق أمام التلاميذ في الصف.

المرحلة الثانية: ينتقل الطفل إلى المقارنة بين ما كتب على اللوحات، وما يكتبه المعلم على السبورة من هذه الكلمات، ومثال ذلك أن يضع الطفل اللوحات المكتوب عليها في صندوق، ومن ثم يكتب إحدى الكلمات على السبورة، ومن ثم يستخرج تللك اللوحة من الصندوق. المرحلة الثالثة: يطلب من الثنلاميذ في هذه المرحلة كتابة ما يثـاهدونه أثناء درس الملاحظة، بحيث ييدأ المعلم في تعليم الأطفال الكتابة غييا، فيقوم بكتابة الكلمات المر اد تعلمها على السبورة، ويطلب من التلاميذ النظر إليها لفترة وجيزة، ثم يقوم بمحوها ويطلب من التلاميذ كتابتها غيبا من ذاكرتهم، على أن يقوم بتكرار ذلك عدة مرات حتى يتمكن التلاميذ من كتابة الكلمات المطلوبة بشكل صحيح. المرحلة الرابعة: هنا يعطي المعلم التلميذ عددا من الجمل التي تحتوي على كلمات ناقصة الحروف أو جمل ناقصـة الكلمات، ويطلب 
وخلاصة القول، إن طريقة (ديكرولي) تعتمد على الربط بين الكتابة والقر اءة بحيث لا يمكن تعليم كتابة جملة، أو كلمة، إلا بعد تعلم

قر اءة تلك الجمل، أو الكلمة والتطبيق السليم لها.

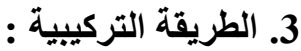

وقد نادت بها المربية (منتسوري) بحيث تعتمد على تعليم الكتابة مثل القراءة عكس الطريقة التحليلية, وتبرر منتسوري ذلك بأن قدرة الطفل على وضع الحروف التي تتكون منها الكلمات بجانب بعضها أكبر من قدرته على قر اءة وفهم هذه الكلمـة، وتتلخص هذه الطريقة في أن يقوم المعلم بكتابة بعض الأسماء والأشياء المألوفة لدى التلاميذ على بطاقات بخط كبير، ثم يتعرف الطلاب النطق السليم لهذه الحروف، ويطلب منهم قر اءة هذه الحروف ببطء، ثم الانتقال إلى قراءة تلك الحروف بشكل سريع للوصـول إلى نطق الكلمة كاملـة ومعرفة معناها, وبعد ذلك توجد الكلمة تحت الأشياء التي تدل عليها، وبعد إتقان الكلمة ينتقل إلى قر اءة الجمل بالطريقة نفسها. (الأسطل،

$$
\text { (52- } 51: \text { : 2010، }
$$

وكمـا أن هنـاك طرقـا عديدة لتعليم الكتابـة، فهناك العديد من الوسـائل المسـاعدة و الميسرة لتعليمها، كالأنشطة اليدويـة في ريـاض الأطفال، و العجين و الصلصال، و الصور و الرسوم والقصص، إلى الحاسوب وتخطيط القر آن الكريم، وقد أثبتت ذلك در اسـات عديدة ـ لا يسعنا ذكر ها في هذه الورقة - وبينت أثر بعض هذه الوسـائل أو الأنشطة في تعلم الكتابـة أو إحدى مهار اتها من خط أو إملاء أو تعبير

\section{خامسا - مهارات الكتابة}

إن تعليم الكتابة يتم عبر مر احل متدرجـة من تعليم البسيط إلى المعقد، وهذه المر احل قد تتطلب سنوات التعليم الابتدائي بأكملها، وحتى يتم تعليم الكتابة بشكل سليم وفعال، فقد قسمت إلى مهار ات أساسية يجب العناية بتدريسها و إتقانها من طرف التلميذ لكي ينمكن في الأخير من التو اصل الكتابي الجيد، و هذه المهار ات هي: مهار ات الخط و إجادته، مهار ات الإملاء و الكتابة الصحيحة، و أخير ا مهار ات التعبير الكتابي عن الأفكار والمعلومات بوضوح ودقة.

وقد اختلف المهتمون بطرق تدريس اللغة العربية و التربويون في تسمية وتصنيف مهار ات الكتابة، فنجد مثلا علي مصطفى (2002) يقسمها إلى مهار ات عامة، تلزم الإنسان في كل أنماط الكتابة الثخصية والأدبيـة والعلميـة والوظيفيـة ومهار ات خاصـة، تلزم لنوع معين من أنواع الكتابة. 
فيقول مصطفى: "للكتابـة مهار ات عامـة يجب توفر هـا لدى كل كاتب، ومهار ات خاصـة يحتاجها كل من أراد القيام بـأداء معين" وذكر مصطفى 27 مهارة فرعية في المهار ات العامة و عند التدقيق في هذه المهارات نجد أنها تتقسم تحت ثلاثة محاور رئيسـة هي الخط و الإملاء و التعبير الكتابي، فقد كان تقسيم مصطفى تحليلا لهذه المهارات.

أمسا بالنسبة للمهار ات الخاصـة: فقد ذكر ستاوثثلاثين قدرة أو مهارة مختلفة, حسب المجالات المهنية و العلميـة والثقافيـة المختلفة (مصطفى، 2002، ص : 164 -165). أما الديلمي و الو ائلي (2005)، الزيات (1998)، عطية (2007)، والهاشي (2008)، مجاور (1998)، فضل الله (1998)، الفار و غطانَة (2001)، فقد قسموا مهار ات الكتابة إلى: مهار ات الخط، مهار ات الإملاء أو التهجي واستخدام علامات الترقيم، مهارات التعبير الكتابي. نتناول هذه المهار ات الثلاثة بشكل من التفصيل فيما يلي : 1

إن الخط و الكتابة وجهان لعملة واحدة، فلا نستطيع الفصل بينهما، وهو الجانب الملموس المحسوس القابل للقياس الموضوعي، وإن الخط الواضح والجميل يسهم في وصول المعنى من الرسالة المكتوبة إلى القارئ بشكل صحيح، حنى أن جمال الخط قد يحفز القارئ على القر اءة وربما محاولته تجويد خطه.

عرفه فضل الله: "بأنه رسم هندسي متعارف عليه، عبارة عن دوائر، ومنحنيات، ونقاط، وخطوط مستقيمة، مـع التزام مـا تواضع عليه العلماء من أشكال هندسية محدة في رسم الحروف". (فضل الله، 1998، ص : 181). وقد ذكر عبد الباري عدة تعريفات للخط كما يلي: (عبد الباري، 2010، ص : 132 - 133). ـ بأنه مهارة حركية وفنية يستعين بها الكاتب لنقل الأفكار بوضوح وبسر عة وبجمال للآخرين. ـ أنه وسيلة الاتصال التي يصب الكاتب من خلالها ما لديه من أفكار ومعلومات وبيانات على الورق. ـ بأنه صناعة من جملة الصنائع البشرية تتميز بالجمال و الوضوح و السر عة. ب ـ الأهداف والمستويات في تدريس الخط: 
إن لتدريس الخط في المدرسة أهدافا متعددة، لكن يبقى الوضوح و السر عة و الجمال في الخط من أهمها.

وحدد الباحثون الأهداف التي يرمي إلى تحقيقها تعليم الخط في ثلاثة أهداف رئيسة هي: الوضوح، والسر عة، و الجمـال، وليس هناك اتفاق بين المربين أيهم أكثر أهمية, ويقول علي مجاور البعض يرى إعطاء الأهمية الأولى للسرعة, و البعض يرى أن الوضوح هو الأهم و ون ثم يجب الاهتمام به أولا، و هذا الر أي فيما يبدو هو الأكثر تلاؤما مـع العملية التعليمية، فإذا مـا أحس المدرس بـأن التلاميذ يكتبون بوضوح، يتجه بعد ذلك إلى السرعة. (مجاور، 1998، ص : 213). ب. 1. الوضوح: هو رسم الحروف رسما لا يجعل للبس محلا، و هي مر اعاة التتاسب بين الحروف طو لا و اتسـاعا، وعلى البعد بين الكلمات في مسافات ثابتة، و على اتباع قو اعد رسم الحروف، وتطبيق أصسول الكتابـة السليمة في وضع النقط والهمزات، ومر اعاة حجم الحرف، وكيفية اتصاله بغيره، وبيان أجزائه، وميله، واستقامته، وطوله وقصره. (فضل الله، 1998، ص : 183). و على هذا فالوضوح مستويات عديدة، وهو نتيجة مجموعة من العو امل المتشابكة، ولقد حس أحد المدرسين الأمر فقال: لو استطعت أن أقرا ألمكتوب بسهولة، إذا فالخط واضح جيد. (مذكور، 2000، ص : 270). ويذكر مجاور ثلاثة معايير يمكن الحكم بها على مستوى الوضوح في الكتابة. 1. وضوح كتابة التناميذ للقارئ وبخاصة في السنة السادسة ابتدائي وما بعدها، ويمكن للمدرس وبخبرته ونظرته أن يعرف مستوى هذا الوضوح. 2. ما يلاحظ على هذه الكتابة من القر اء أنفسهم. 3. رأي التلميذ نفسه فيما يكتب. (مجاور، 1998، ص : 216 - 217). ب. 2. السرعة: وهي إرسال اليد في سهولة ويسر بسرعة مناسبة. (فضل اله، 1998، ص : 183). إن السر عة تعتبر في المرتبة الأولى من الأهمية بالنسبة للكاتب أما الوضوح فأهميته لكل من الكاتب والقارئ على السواء، والسرعة للكاتب توفر له الوقت و الوضوح يبرز أفكاره. وفي بعض البحوث التي أجريت لتعرف مدى السر عة أو متوسطها في سنوات الدر اسـة المختلفة، وقد كان المعيار متوسط عدد الحروف التي تكتب في كل سنة در اسية في الدقيقة الواحدة، وقد استعملت هذه الطريقة في بعض مدارس القاهرة بالمرحلة الإعدادية، وقد لوحظ أن متوسط السرعة يزداد مع السنوات الدراسية من 60 في السنة الأولى إلى 65 في الثانيـة، ليصل إلى 72 في السنة الثالثة، أمـا 
الكبار فيمكنه أن يصلوا إلى 120 حرفا في الاقيقة، كل هذا دون نقص في الوضوح أو أسس الجمال. (مجاور، 1998، ص : 215 -

ب. 3. الجمال: أما الجمال فمن الصعب قياسه، و الحكم على الخط بأنه جميل مسألة تختلف من شخص لآخر، فما أر اه خطا جميلا قد ير اه آخر أنه عادي أو واضح فقط.

ويقول عنه مجاور: "ليس من السـل مقياسـه إلا معيار الذوق و الإحسـاس بـه، وليس معنى ذللك أن نحكم في الحكم كتابـة التناميذ بالأنماط الفنية والقو اعد التي وضعها علماء الخط وفنانوه، و الجمال من غير شك أمر مرغوب ومحبب ولكن لا يمكن أن يتوفر لكل فرد؛ لأنه يتوقف على استعدادات خاصـة ومهار ات معينة, وإن كان هذا لا يمنع من أن ينظر إلى الجمال بمعيار يتلاءم ومستويات التلميذ المتعلم، ومعنى هذا أن ننظر إلى الجمال الفني في الخط بالنسبة لتلاميذ المرحلة الابتدائية وتلاميذ المرحلة الإعدادية بالمعيار السهل الذي بتطلب من المتعلم جها و لا إلماما بقو اعد في الفن الخطي. (مجاور، 1998، ص : 214). وقد حدد مجاور معايير يمكن أخذها بعين الاعتبار للحكم على الخط بأنه جميل وهي:

1. التنظيم: فالكتابة المنظمة المرتبة يبدو فيها عنصر الجمال و اضحا، كما أن التنظيم في ذاته من أهم مقومات الجمال في أي شيء. 2. الوحدة: معنى هذا أن يكون هناك تتاسق فيما يكتبه الكاتب المتعلم، فلا نكتب كلمة غير ملائمة مع غير ها من الكلمات ويبدو حرف أكبر أو أصغر من أمثاله.

3. التوازن في عملية الكتابة: فلا يكتب حرف أبرز من حرف آخر أو يكتب حرف بخط يغاير بقية حروف الكلمة وهكذا، و المقصود أن تكون عملية الخط كعملية التلوين في الرسوم لا يليق أن يكون هناك عدم انسجام أو تلاؤم فيما بينهما. 4. التأثير في القارئ: بمعنى أن يأخذ القارئ بالخط وينأثر به. (مجاور، 1998، ص : 214 - 215).

\section{ج ـ طرق تلريس الخط وخطواته:}

ولتحقيق الأهداف السابقة يجب أن تكون هناك طرق منظمـة ومدروسـة لتعليم الخط للأطفال، مر اعين فيها كل جو انب الشخصية، و أولها الخصائص الجسمية الفيزيولوجية، ثم بعدها تكون المادة المتعلمة مما يميلون إلبه وير غبون في كتابته، وبذلك فهناك مجموعة من الأسس يجب مر اعاتها عند تدريس الخط العربي منها:

1. مر اعاة البيئة الفيزيائية المحيطة بالفرد من حيث: طريقة الجلوس، نوعية المقعد، الإضاءة، التهوية، نوع المداد، ونوع الورق. 
2. اختيار القلم المناسب الذي سيكتب بـه الطالب، وذلك عن طريق إبعاده عن الأقلام الجافـة والخشنة، أو الأقلام التي لا تتناسب وحجم يد الطالب.

3. اختيار المادة التي تقدم للتلاميذ لكتابتها، وكلما كان ما يكتبه التلميذ مما يحب كتابته ويرغب فيه كان ذلك أدعى للتطور و النجاح

4. التكرار ، فالخط عملية لا بد أن يأخذ التكرار دوره؛ إذ بدونه لا يمكن أن يصل التلميذ إلى التعلم المطلوب.

$$
\text { 6. 5. أبدء بتعليم الكلمات و الوحدات الكبرى بدلا من الحروف. }
$$

$$
\text { 7. التشجيع على الكتابة في غبر أوقات حصة الخط. }
$$

ويحدد فضل الله طريقة لتدريس الخط للأطفال من المبتدئين, وذلك باستخدام طريقة واحد ـ ثلاثنة: طريقة تجزئة الحرف، طريقة الحرف، طريقة الكلمة.( فضل الله، 1998، ص : 184).

رغم أن المختصين في طرق التدريس حددو الطرقا مختلفة لتعليم الخط، إلا أننا نقول أنه لا يمكن التقيد بطريقة محددة للتدريس في أية مادة تعليمية، وذللك لاختلاف الأهداف التي يصفها المدرسون واختلاف خصائصسهم وخصـائص المجتمع، و التلاميذ، وحتى الوسـائل المنوفرة للتدريس.

ويتفق التربويون على أن تدريس الخط يتم على مر احل متدرجة من السهل إلى الصعب، أي من رسم الحروف و الكلمات على نحو صحيح إلى القدرة على الاسترسال في الكتابة دون تقليد نموذج ودون أخطاء، وهذا مع مر اعاة سن التلميذ وقدراته الجسمية والعقلية. ويؤكد علي مجـاور (1998) أن تعليم الخط يستحسن أن يكون في أولـه سهـلا متـدرجا نحو الصـوبة، وهذا يكون في المرحلـة الابتدائية و الإعدادية، أما الخط بمفاهيمه الفنية فميدانه المرحلة الثانوية.

ولهذا فمن الصعب تقييم جودة الخطوجماله في مر احل التعليم الأولى (الابتدائي والمتوسط)؛ لأن التلميذ ماز ال في طور النمو على كل الأصعدة الجسمية و النفسية و العقلية، فلبس من المنصف أن نحكم على خطهم، وهم لا يحكمون السيطرة على قبضـاتهم وحركات أبيدهم و أصابعهم. 
إن كان وضوح الخط من الأهداف الأساسية في تعليم الكتابة للمبتدئين، فإن صحة وسلامة الكتابة من الأخطاء لا يقل أهمية، فالخطأ الإملائي يشوه الكتابة ويعيق فهم الرسالة المكتوبة، وإذا كانت القواعد النحوية وسيلة لتقويم اللسان والقلم من الزلل فبإن القواعد الإملائية وسيلة لتقويم القلم وصحة الكتابة من الخطأ.

\section{أ ـ ت تعريفهِ:}

و الإملاء هو الرسم الصحيح للكلمـات، و الكتابـة الصحيحة تكتب بالتدريب و المر ان المنظم ورؤيـة الكلمـات، و الانتباه إلى صور ها وملاحظة حروفها ملاحظة دقيقة، واستخدام أكثر من حاسـة في تعليم الإملاء، لتنطبع صور الكلمـات في الذهن، ويصبح عند الطالب مهارة في كتابة الكلمات بالثكل المطلوب، وقد يعرف الإملاء على أنه تحويل الأصوات المسموعة المفهومة إلى رموز مكتوبـة على أن توضع هذه الحروف في مو اضعها الصحيحة من الكلمة، وذلك لاستقامة اللفظ وظهور المعنى المراد، ويعتبر الإملاء مقياسا دقيقا لمعرفة المستوى الذي وصل إليه الصغار في تعلمهم. (عاشور و الحوامدة، 2007، ص : 125). ويعرفهـ عبد الرحمـان الهاثـمي بأنـه: عمليـة إتقان رسـ الحروف و الكلمـات عند كتابتها لتصبح مهارة يكتسبها المتعلم بالتـريب و المر ان، وتحتاج إلى عمليات عقلية، جمالية، أدائية تسهم فيها البيئة المدرسية والثقافية. (الهاشمي، 2008، ص : 185). ب ـ مهارات الإملاء: n يحدد فضل الله (1989) المهار ات الإملائية التي ينبغي أن بتقنها تلاميذ التعليم الأساسي:

$$
\text { ـ ـ مهار ـ مهار ات المد (بالألف، بالو او، بالياء). }
$$

ـ مهار ات رسم الهمزة: الهمزة في أول الكلمـة الهمزة المتوسطة على السطر، والألف، والواو، و النبرة- الههزة المنطرفة على السطر ، والألف، و الواو، و الياء.

ـ مهار ات استخدام علامـات الترقيم: الفاصلة، الفاصلة المنقوطة، النقطة، علامـة الاستفهام، علامـة التعجب، النقطتان الر أسيتان، علامة التتصيص، الثرطة، القوسان، الثرطتان. 


$$
\begin{aligned}
& \text { ـ مهارة رسم الكلمات التي بها حروف تنطق و لا ترسم أو التي بها حروف نرسم ولا تنطق. } \\
& \text { ـ مهار ات الرسم القرآني. (فضل الله، 1998، ص : 155) } \\
& \text { ويضيف لها ماهر شعبان عبد الباري (2010) المهار ات التالية: } \\
& \text { ـ التمبيز بين هزني الوصل و القطع. } \\
& \text { ـ التمبيز بين (الل) الثمسية و القمرية. }
\end{aligned}
$$

ـ التمبيز بين التاء المفتوحة والمربوطة. (عبد الباري، 2010، ص : 115).

ويختلف تناول هذه المهار ات في المدارس الابتدائية من بلد عربي إلى آخر، لكن بيقى الاتفاق على التدرج من المهار ات السهلة كمهار ات المد و التنوين و التاء المفتوحـة والمربوطـة... إلى المهارات الصـبة و التي يتفق أغلب المدرسين بأنها مهار ات كتابـة الهـزة

\section{ج - أنواع الإملاء وطرق تدريسها:}

يتنوع الإملاء بتنوع هدفه ووظيفته، فهناك من يقسمه إلى أربعة أنواع هي الإملاء المنقول، والإملاء المنظور، الإمـلاء الاستماعي، و الإمـلاء الاختبـاري، و هنـاك من يضـيف لها نو عـا خامسـا وسادسـا همـا الإمـلاء الاستباري و الإمـلاء التعليمس، نتنـاول الأنواع الأربعـة الرئيسة التي يتفق عليها العديد من التربويين والمختصين في طرق تدريس اللغة العربية.

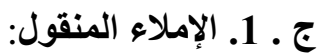

ويكون بعرض نص على السبورة أو في بطاقات خاصة أو في كتاب معين، ثم يقرأ هذا النص ويناقش، ويتولى المعلم تحليل بعض الكلمـات وتهجئتها وتوضيحها شفهيا، ثم يبدأ التلاميذ بعد ذلك بنقل النص في كر اسـات خاصـة، ويجب هنـا مر اعـاة أن تكون القطعـة المختارة ملائمسة لإدر الك التلاميذ ومستوى نضجهم، فضـلا عن اتصـال هذا النص بحياة التلميذ وبيئته، ويصلح هذا النوع من الإمـلاء

$$
\text { للصفوف الأولى والثانية. (الدليمي و الو ائلي، 2005، ص : 121). }
$$

أمـا الهاشـمي فيقول أن هذا النوع مـن الإمـلاء يناسـب الصف الثالث, أمـا الصفان الأول و الثاني فـلا يخصص لهمـا حصص إمـلاء.

$$
\text { (الهاشمي، 2008، ص : 186). }
$$


ويضيف عطية "عندما نقول أن هذا النوع بستخدم في المراحل التعليميـة الأولى, فإن هذا لا يعني عدم استخدامه في المراحل الدراسية التالية، فهو ضروري في كل المراحل الدراسية في غير دروس الإملاء، لذا فإن التنريب على النسخ، أو النقل أمر مهم للتمكن من الكتابة؛ لما له من دور مهم في تثبيت صور الكلمات في أذهان المتعلمين". (عطية، 2007، ص : 230).

من مز ايا الإملاء المنقول أنه يعتمد على الملاحظة والمحاكاة, وبما أن النقل يكون بتعويد الطفل النظر إلى الكلمات وتقليد نسخها على الدفاتر فهذا بدوره يقوي انتباه الطلبة وملاحظتهم. (عاشور و الحوامدة، 2007، ص : 134).

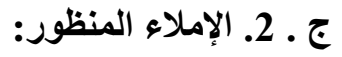
ومعناه أن تعرض القطعة على التلاميذ لقراءتها وفهمها و هجاء بعض كلماتها، ثم تحجب عنهم، وتملى عليهم بعد ذلك، و هذا النوع يناسب الصف الر ابع ويمكن أن يدرس للصف الخامس. (الهانشي، 2008، ص : 186). ويمكن للمعلم في هذا النوع من الإملاء أن يقي على بعض الكلمات الصعبة جزئيا أمام التلاميذ زمنا كافيا للنظر إلى النص لترسخ صور الكلمات في أذهانهم، ويأتي هذا النوع من الإملاء بعد أن يكون المعلم قد ثبت من أن تلاميذه تدربوا بصورة كافية على الإملاء المنقول. (الدليمي والو ائلي، 2005، ص : 122). ومن مز ايا هذا الإملاء أنه يساعد التناميذ على الربط بين النطق والرسم الإملائي، كما أنه يعتبر خطوة متقدمة في سبيل التهيؤ. ل الجة الصعوبات الإملائية.

\section{ج - 3. الإملاء الاستماعي (المسموع):}

إن هذا النوع من الإملاء ينتقل بالمتعلمين من الاعتماد على حاسة البصر ، وتذكر الصور البصرية إلى حاسة السمع، والربط بين الرموز الصوتية للكلمات، وصور ها التي يفترض أنها قد علقت في ذاكرتهم من خلال قر اءتها سابقا. (عطية، 2006، ص : 230). إن هذا النوع من الإملاء تلد تسميته عليه، فالنص لا يعرض على التلاميذ بل يكتفي المعلم بقر اءته على مسامعهم ثم تناقش معانيه وتر اكيبه اللغوية التي تضمنها، و على المعلم أن يقرأ القطعة الإملائية قراءة جهرية نموذجية قبل البدء بمناقثتها، وبعد أن يعرف التلاميذ فحوى هذا النص يملى عليهم، وهذا النوع يصلح لتلاميذ الصفين الخامس و الساد. (الدليمي و الو ائلي، 2005، ص : 123).

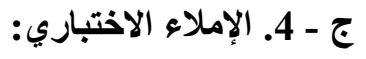
ويعني أن يكتب الطلبة قطعة إملائية يمليها عليهم المعلم من دون أن يسبق لهم أن رأوها، أو سمعو ها قبيل التملية، و الغرض منه 


$$
\text { كما يعتمد تدريس الإملاء بصفة عامة ـ كفرع من فروع الكتابة ـ على مجموعة من الأسس منها: }
$$

ـ جلوس التلاميذ جلسة مريحة وصحيحة، و إمساك القلم بالثكل السليم و الاهتمام بالخط الجيد والتنظيم و النظافة. (الهاشمي، 2008،

$$
\text { ـ العناية بالعلاج الفردي لضعاف التلاميذ. }
$$

ـ الاهتمام بالمعنى قبل التهجئة عن طريق ربط الإملاء بالأعمال التحريرية.

ـ تناول الإملاء تتاو لا عمليا يحقق المنفعة للتناميذ.

$$
\text { ـ تأكيد فهم النص المكتوب من طرف التناميذ. }
$$

$$
\text { ـ القراءة الجهرية للنص الإملائي. }
$$

ـ التركيز على الميسر من القو اعد الإملائية والابتعاد عن الثاذ منها. (الهاشمي، 2008، ص : 191).

\section{دـ ـ الأخطاء الإملائية وأسبابها:}

رغم مـا توليه المدرسـة من اهتمـام كبير بهذه المهارة الكتابية، والطرق التدرييية المختلفة، و الوسـائل التوضيحية المسـاعدة، تبقى الأخطاء الإملائية تظهر في كتابات التلاميذ سواء في المرحلة الابتدائية أو حتى لدى طلبة الجامعة.

$$
\text { ومن الأخطاء الإملائية الثائعة في كتابات التلاميذ في كل المر احل التعليمية: }
$$




\section{2 ـ أخطاء في كتابة الكلمات التي تتضمن حروفا تنطق و لا تكتب مثل أسماء الإشارة وغير ها. 3 ـ أخطاء في كتابة الهزةة المتطرفة بأثكالها المختلفة (على الياء، والواو، والألف، والسطر). 4 ـ كتابة الحركات حروفا مثل: كتابة الفتحة ألف أو هاء...} 5 ـ إسقاط الألف التي ترد بعد واو الجماعة في الأفعال وكتابتها بعد واو الجماعة في جمع المذكر السالم المضاف. 6 ـ كتابة الضاد ظاء، و الظاء ضاد. 7 ـ كتابة التاء المربوطة مفتوحة و التاء المفتوحة مربوطة. 8 ـ كتابة التنوين نونا. 9 - إسقاط همزة الوصل. 10 - إسقاط اللام من (الل) التعريف عندما يسبقها حرف جر. 11 ـ إسقاط الهمزة من (الل) التعريف عندما يسبقها حرف جر. 12 ـ الخلط بين همزة القطع و الوصل. 13 ـ الخلط بين الحروف المتقاربة في الصوت. (عطية، 2007، ص : 149-150). ويذكر أمين بركات عن (الخولي 1988، سعيد 1988، فرحات 1997، الضـامن 1998، Perris 2001، Pray، الصو الي 2002 2003، Chandler أسباب الضعف في الإملاء: 2003 1 ـ تدريس الإملاء يقوم في كثير من البلدان العربية على أساس فلسفة اختيارية لا فلسفة تعليمية إجبارية.

2 ـ تدريس الكتابة الإملائية لا يقوم على أساس علمي يقسم إلى مر احل تعليمية تمتد من مرحلـة مـا قبل المدرسـة إلى نهايـة المدرسـة المتوسطة، بحيث يتم توزيع المهار ات الإملائية والخطية وقيم الكتابة و عاداتها السليمة على هذه المر احل العمرية. 3 ـ أساليب تدريس الإملاء تقتصر غالبا على الإملاء المنقول والمنظور والاختباري، ولم تمتد هذه الأسـاليب إلى طرق أخرى ثبت نجاحها في بعض اللغات الأجنبية ويمكن استخدامها في تعليم الكتابة العربية، من مثل أساليب التعلم الذاتي والفردي و الإرشادي. 
4 ـ فكرة الاستعداد للكتابة ودور ها في تدريس الكتابة الإملائية لم تلتفت إليها منـاهج الكتابـة الحالية رغم جدواها وأهميتها في تعليم الكتابة الإملائية.

5 ـ اقتصار نركيز قو اعد الإملاء في التدريس على الهمزات بأنو اعها والألف اللينة, دون الاهتمام لظواهر إملائية كثيرة منها المد

$$
\text { والتنوين و إبدال الحروف المتقاربة وقلب الحركات و علامات الترقيم وغير ها. }
$$

6 ـ تعليم الكتابة الإملائية لا ير اعي مبدأ الفهم قبل الكتابة. (بركات، 2008، ص : 5 - 6).

ويمكننا القول أن أغلب الدر اسات التي تناولت الإملاء بشكل عام أو الخطأ أو الضـعف في الإمـلاء قد بينت انخفاض مستوى الأداء الإملائي لدى التلاميذ في مختلف المر احل التعليمية بما فيها المرحلة الجامعية.

أما عن أكثر الأخطاء الإملائية شيو عا لاى التلاميذ فهي رسم الهمزة بمو اضعها الثلاث، وأن نسبة الخطأ تقل كلمـا ارتفع المستوى التعليمي، بالإضافة إلى تأثثير متغير ات الجنس والصف و التحصيل الدراسي، وتحفيظ القرآن في إتقان المهارات الإملائية و التقليل من

أما عن أسباب الأخطاء الإملائية حسب التربويين فبعضهم يرجعها إلى: طريقة التدريس الثائعة، قلة شرح قو اعد الإملاء للكلمات الصعبة على السبورة، قلة حجم الموضوع الإملائي، و البعض الآخر يرى أن هنالك العديد من الأسباب, منها مـا يعود للمعلم، ومنها مـا يتصل بالتلميذ، و منها ما يعود لخصائص اللغة العربية، وطريقة التنريس، ومنهج الإملاء المتبع. 3 ـ التعبير الكتابي:

إن التعبير بصفة عامة بشكليه الثفهي و الكتابي هو الهدف الأساسي لتعليم اللغة، فكل فنون اللغة ومهار اتها تصب في التعبير، و على هذا فالقر اءة والاستماع و الحديث و النحو والصرف وصحة الإملاء وجودة الخط كلها وسائل لغاية واحدة هي التعبير الكتابي الجيد، فنحن نحكم على التلميذ أو الطالب بأنه يتقن اللغة العربية، إذا كان قادر اعلى التعبير الكتابي بأسلوب صحيح و أفكار متسلسلة منطقيا، وعبار ات و مفردات متنو عة، و لا يكفي جمال خطه أو صحة إملائه لكي نحكم على جودة تعبيره، و التعبير الكتابي باعتباره إحدى صور الكتابـة، يعد وسيلة اتصال الفرد بغيره ووسيلة للفهم والإفهام، وهو أساس التفوق الدراسي في المجال اللغوي.

أ ـ تعريفه:

ويعرفه عطية (2007): " هو الكلام المكتوب الذي يصدره المرسل كتابة، ويستقبله المستقبل قراءة، ويستخدم غالبـا في مواقف التباعد بين المرسل و المستقبل زمانا ومكانا". (عطية، 2007، ص : 277). 
ويعرفه الدليمي و الو ائلي (2005): "عبارة عن اتصـال الفرد بغيره بشكل كتابي، وهو النوع السـائد و المـألوف في المدارس بشكل عام، ومن مهار اته وضوح الصيخة في العبار ات و التر اكيب وسلامة الكلمات و الجمل من الأخطاء الإملائية و النحوية".

يتفق المهتمـون بتدريس اللغـة العربيـة أن أهداف التعبير الكتابي ترتبط ارتباطـا وثيقا بأهداف اللغـة العربيـة؛ لأنـه المحصلة النهائيـة لدر استها، كما تختلف أهداف التعبير الكتابي من مرحلـة تعليميـة إلى أخرى فأهداف تدريسـه في المرحلة الابتدائية تختلف عنها في المرحلة الإعدادية و الثانوية، وكذلك حسب طبيعة هؤ لاء التلاميذ واحتياجاتهم للكتابة، واتجاهاتهم وميولهم نحو ها، واستعداداتهم الثخصية وظروفهم الثقافية والاقتصادية والاجتماعية، لذا نجد أهداف تدريس التعبير الكتابي تختلف من بلد عربي لآخر، كذلك الأنشطة الكتابية التي تمثلك من كتابة رسالة، أو قصة أو كتابة الخطابات و الملخصات و المذكرات و التقارير و غبر ها.

\section{ب ـ مهارات التعبيز الكتابي ومقومات التعبير الجيد:}

$$
\text { ويقسم الهاثمي (1995) مهار ات التعبير إلى أربعة أقسام تتدرج تحتها مهار ات فرعية هي كما يلي: }
$$

ـ مهار ات ترتبط بالمفردات وفيها: (استخدام كلمات عربية فصيحة، تجنب الألفاظ العامية، نبذ الأخطاء الثـائعة أثناء الكلمات، رسم

$$
\text { الكلمات رسما إملائيا صحيحا، الصياغة الصرفية الصحيحة). }
$$

- مهار ات ترتبط بالتركيب و الأسلوب وفيها: (استخدام أدوات الربط بدقة، اكتمال أركان الجملة، سلامة التركيب النحو، صحة

$$
\text { الأساليب المستخدمة). }
$$

ـ مهار ات ترتبط بالأفكار وفيها (صحة الأفكار و المعلومات، وضوح الأفكار، استيفاء عناصر الأفكار، نرابط الأفكار وتسلسلها).

ـ مهار ات ترتبط بالتنظيم وفيها: (استخدام نظام الفقرات، استخدام فكرة لكل فقرة، وضوح الخط، استخدام علامـات الترقيم، سـلامة

$$
\text { الهو امش وتناسقها). (الحلاق، 2007، ص : } 73 \text { - 74). }
$$

ويضيف عطية (2007) أن هناك لوازم أخرى يجب نو افر ها في التعبير الكتابي زيادة على الأسلوب و الفكرة وهي: تنظيم الفقرات و العبار ات و إتقان علامات الترقيم ووظائفها ومواضع كل منها، زيادة على حسن الخط، ونظافة الورقة، لذا يرى عطية من الملائم تذكير مدرس اللغة العربية بعلامات الترقيم ومو اضع استخدامها، لا سيما أنه أجرى در اسـة على خريجي قسم اللغـة العربيـة حول مدى تمكنهم من علامات الترقيم، فوجد أن هنالك ضعفا واضحا لديهم في مستوى تعاملهم مع هذه العلامات.

$$
\text { إن مهار ات التعبير الكتابي ومقومات التعبير الجيد سوف تتضح أكثر عند عرض أنواع التعبير الكتابي فيما يلي: }
$$




\section{ج - أنواع التعبير الكتابي:}

يقسم التعبير الكتابي من حيث الموضوع إلى تعبير وظيفي وإبداعي، وكلاهما لا يقل أهميـة عن الآخر ، رغم أن بعض المنـاهج الخاصة بتدريسها ترتكز على أحدهما وتهمل الآخر.

\section{ج. 1. التعبير الكتابي الوظيفي:}

و هو الذي يؤدي غرضـا وظيفيا تقتضيه حياة المتعلم داخل المدرسـة وخارجها، أب أنـه كتابـة تتصل بمطالب الحياة مثل: كتابـات الخطابات الرسمية، أو التقارير أو البرقيات، وهو نوع من التعبير لا يمكن الاستغناء عنه لأنه يرتبط باحتياجات حياتية يومية. (فضل الله،

ويضيف محسن عطية أن التعبير الكتابي الوظيفي يستخدم في المو اقف ذات الطابع الوظيفي الكتابي مثل: الرسائل والخطابات ذات الطابع المصلحي، البرقيات، تقارير العمل، ملء استمارة معلومات، كتابـة الطلبـات إلى الجهات الرسمية لأغر اض الحصول على أمور يحتـاج إليها الفرد و غير هـا، و هو لا يستلزم التصنع و التزويق ولا ينشـ الجمال إنما يرمي إلى تحقيق المقاصد الوظيفية بأقصر الكلام و أيسره، و أكثره وضوحا عند المتلقي، ويمكن صاحبه من قضاء حاجاته اليومية. (عطية، 2007، ص : 228-229).

ومن خلال نتائج بعض الدر اسات حول مهار ات التعبير الوظيفي، ومن خلال تجربة الباحثة في التعليم الجامعي، يتضـح أن الضـف في التعبير الكتابي الوظيفي لا يقتصر فقط في المرحلة الابتدائية أو الثانوية بينما يتعداه إلى طلبة الجامعة؛ حيث نلمس لدى الطلبة العجز و الضعف في كتابة التقارير و الملخصات العلمية وحتى طلب خطي بسيط، و هذا راجع ربمـا - وحسب مـا توصلت إليه بعض الدراسـات في هذا المجالـ إلى عدم تحديد مهار ات التعبير الكتابي الوظيفي ومجالاته في منهاج اللغة العربيـة في التعليم الجزائري في كل أطواره، كل مجال لمرحلة تعليمية معينة، والتركيز على مهار ات التعبير الكتابي الإبداعي فقط، وإهمال تدريس هذه المهارات من طرف المعلمين.

$$
\text { ج. 2. التعبير الكتابي الإبداعي: }
$$

يتم عن طريقه التعبير عن المشـاعر الأحاسبس والخو اطر بأسلوب أدبي مشـوق ومثير، مثل كتابـة الثـعر والقصص والمقالات الأدبية، و هو ينمي الخيال ويساعد على الإبداع ويحافظ به المتعلم على جمال اللغة وينمي تذوقه لها. (فضل الله، 1998، ص : 144). ويقول عاثور و الحوامدة أنه: "هو الذي يكون غرضه التعبير عن الأفكار والمشاعر النفسية ونقلها إلى الآخرين بأسلوب أدبي عالٍ، بقصد التأثير في نفوس القارئين والسـامعين، بحيث تصل درجـة انفعالهم بها إلى مستوى يكاد يقترب من مستوى انفعـال أصحاب هذه 
الآثار، و إذا كان التعبير الوظيفي يفي بمنطلبات الحياة وشؤونها المادية والاجتماعية، فإن التعبير الإبداعي يعين الطالب على التعبير عن نفسه ومشاعره تعبير ا يعكس ذاته وييرز شخصيته. (عاشور و الحوامدة، 2007، ص : 202 - 203).

ويعتمد هذا النوع من التعبير على العبارة المنتقاة، واللفظ المصقول واستخدام الصور الخيالية، والتعبير عن الأفكار والأحاسبس بطريقة فنية تتصف بالجمال ورقة الأسلوب ورشاقته، ويتجلى التعبير الإبداعي في نظم الثعر، وكتابة المقالات الذاتية، وكتابـة المذكرات الثخصية، وكتابة القصص العاطفية و المسرحيات والرسائل الوجدانية. (الحلاق، 2007، ص : 71). ولما كان التعبير الإبداعي يقوم على جمال الفكرة، وأسلوب عرضها والتأثثر في القارئ، فإنه يرتكز على عنصرين الأول الفكرة، و الثاني الأسلوب، فأما الأفكار فتأتي من تجارب الطلاب وسعتها، ومسـاحة قر اءاتـه، و اطلاعـ،، ومشـاهداته، أمـا الأسـاليب فهي و الألفاظ أو عية الأفكار ، بها تنتقل من الكاتب إلى القارئ، ومصدر ها القراءات المتنو عة لكتاب مبدعين متتوعين، زيادة إلى تقصي فنون الأدب من خلال و سائل متعددة, كالمحاضر ات, و الندوات, و المسرحيات, و غير ها. (عطية، 2007، ص : 213). وتجمع أغلب الدر اسات التي تتاولت مهار ات التعبير الكتابي بذوعيه الوظيفي الإبداعي على تدني مستوى التلاميذ في هذه المهارات، ويرجعون السبب في ذلك إلى عدم وضوح أهداف تدريس التعبير الكتابي في مراحل التعليم المختلفة، وعدم تحديد المهار ات والمجالات اللازمة لكل مرحلة تعليمية، بالإضافة إلى طرق التدريس المستخدمة وعو امل أخرى متعلقة بالتلميذ.

\section{دـ ـ مداخل تدريس التعبير الكتابي:}

إن تنوع مهار ات التعبير الكتابي ومجالاته يجعلنا نتساءل ما طرق التدريس المناسبة والفعالة لبلوغ الأهداف المرجوة من طرف المعلمين و المتعلمين، وقد تعددت هذه الطرق وتنوعت حسب اتجاهات الباحثين، ونذكر أولا خطو ات تدريس التعبير الكتابي في المدخل التقليدي و المتضمنة في التمهيد والمقدمة واختيار الموضوع، ثم معالجة الموضوع على السبورة، ومناقثة التلاميذ بأسئلة تتعلق بموضوع التعبير وتبرز أفكاره الرئيسـة والجزئية، وتهتم بتوليد الأفكار و المعاني المرتبطة بالموضوع، وتدوين ملخص الموضوع، ثم مطالبة التلاميذ بكتابته في المنزل، ثم تصحيحه من قبل المعلم.

وقد ذكرت سلمى عزازي (2004) نقلا عن حسني عصر (2000) مجموعة من المداخل المستخدمة في تدريس التعبير الكتابي

مدخل قو اعد كتابـة العبارة: ويقوم على مسلمة مؤداهـا أن التمكن من قو اعد اللغـة يعين على التمكن من الكتابـة على نحو أفضل 
مدخل السير الذاتية وجمهور التلاميذ: يقوم على أساس: أن الكتابة عمل ذاتي شخصي قبل أن يكون وظيفيا ذا غرض. مدخل تجزيئي عملية الكتابة: يقوم على أسـاس أن أفضل أسلوب للكتابـة هو تجزئتها إلى مر احل: مرحلـة المسودات، مرحلة النص المبدئي للموضوع، ومرحلة التنقيح و الضبط.

هذا بالإضـافة إلى المـداخل الحديثة المستعملة في التـريس بصفة عامـة، منهـا التعلم التعـاوني، حل المشكلات، التعلم للإتقان، ملفـات الإنجاز , و غير ها.

إذن، مـن خـلال نتائج الدر اسـات السـابقة، يمكننـا القول أن الإستر اتيجيات الحديثة للتعليم مثل: التعلم التعـاوني، وحل المشكلات، و العصف الذهني... و غير ها، أثنتت فعاليتها في تدريس وتتمية مهار ات التعبير الكتابي أكثر من الأسـاليب التقليدية، لذا فمن الأجدى أن يُدرب المعلمون على هذه الإستر اتيجيات التعليمية الحديثة، لكي نحسن من مستوى التلاميذ والطلبة في مهار ات التعبير الكتابي خاصـة و المهار ات اللغوية بصفة عامة.

إن مما لا شك فيه أن للتعبير الكتابي أهمية كبرى في حياة المتعمين، بل هو من مقومـات نجاحهم التعليمي، ورغم تعدد مجالات اسـتخدامه سـواء فـي التعبيـر الـوظيفي، أو الإبـداعي، إلا أنـهـيقـى الاتفـاق على أن المهـار ات الأساسـية للتعبيـر الكتـابي تتـدرج في مستو يين: مهار ات الثكل، ومهار ات المضمون, وتتدرج تحت كل منهما عدة مهار ات. ومن الضروري أن يكتسب تلاميذ الصفوف الابتدائية لبعض هذه المهارات لكي يتمكن من إتقان مهارات التعبير الكتابي في المر احل التعليمية المتقدمة، ورغم الأهمية التي توليها المنـاهج التعليميـة للتعبير بشقيه الثفوي و الكتابي، و الحجم السـاعي المخصص لها، يبقى الضعف و عدم التمكن مسيطر ا على أغلب كتابات تلاميذ المر احل التعليمية المختلفة، وذلك قد يرجع لعدة أسباب منها أسباب ترجع للمعلم وطرق التدريس و التصحيح التي يستخدمها، أو إلى التلميذ وقلة اهتمامه ودافعيته للمادة أو ضعف محصوله اللغوي، أو إلى عو امل أخرى منها الظروف الثقافية والاقتصادية و الاجتماعية للأسرة والمجتمع.

خاتمة:

من خلال ما استعرضناه في هذه الورقة، تبين لنا أن الكتابة عملية معقدة ومتثابكة الجوانب من حيث هي مادة تعليميـة، أو من حيث كونها قدرة لغوية ومعرفية يمتلكها الإنسان، نتطلب نضج و اكتساب العديد من المهار ات و القدرات النفسية والجسمية. وحاولت المناهج و المقررات الدر اسية الخاصـة بتعليم اللغـة العربية، تخصيص حصص مستقلة لمهار اتها من خط وإمـلاء وتعبير كتابي؛ وذلك ليركز المعلم ويهتم بها في برنامجها وطرق تدريسها، ولتفكيك بعض من تشـابكها وتسـهيل وتبسيط لكيفيـة تلقينها وتعليمها 
إلا أنه من الواضح - و هذا ما بينته نتائج الدراسات في هذا المجالـ ضعف و عدم تمكن التلاميذ من المهار ات الأساسية للكتابة خاصة مهار ات الإملاء و التعبير الكتابي, وذلك في كل أطوار التعليم من الابتدائي إلى الثانوي وحتى الجامعي، وترجع هذه الدراسـات سبب ذلك تارة إلى المعلم وطرق تدريسه, وتارة للتلميذ وضعف محصوله اللغوي وظروف أسرته ومجتمعه. مقترحات البحث:

من خلال المعلومات التي استعرضناها في هذه الورقة نقدم بعض المقترحات العملية لتحسين مستوى المتعلمين في الكتابة، ومقترحات نظرية لتطوير و إثراء البحث العلمي في مجال مهار ات الكتابة.

ـ إدر اج مو اد تعليمية خاصة بتعليم مهار ات ما قبل الكتابة مثل: رسم الخطوط و التلوين و القص و الكتابة على الرمل و غير هـا، في مرحلة الروضة لتهيئة الطفل للكتابة مع دخوله المدرسة, و التركيز في هذه المرحلة على الحروف و الكلمات و النصوص في مرحلة متقدمة. ـ تخصيص مادة در اسية لكل مهارة من مهار ات الكتابة, مع التركيز على مهار ات الخط والإملاء البسيطة في المر احل الابتدائية الأولى، و على مهار ات التعبير ومهار ات الإمـاء المتقدمة في المراحل الأخيرة من التعليم الابتدائي وحتى المرحلة المتوسطة، و الوصـول الى مهرات التعبير الإبداعي و الوظيفي في المرحلة الثانوية .

ـ تشجيع وتحفيز التلاميذ و الأطفال على الكتابة بتصميم كر اريس مبهجة وذات تصاميم ممتعة، وتخصيص جوائز تشجيعية لتحفيز هم على الكتابة, سواء على جمال الخط أو سلامة الرسم الإملائي أو البر اعة في التعبير الكتابي. كما نقترح مو اصلة البحث في هذا الموضوع من أجل إثرائه وتوسيع المعرفة في مجال تدريس مهار ات اللغة العربية من خلال: ـ در اسة الموضوع من جانبه غير السوي بدر اسـة كل من مشكلات أو صعوبات أو اضطر ابات الكتابـة في المراحل العمريـة المختلفة سواء الطفولة أو حتى الثيخوخة. ـ دراسة تأثثر بعض العو امل النفسية والاجتماعية والمعرفية على تعلم مهار ات الكتابة و إتقانها. ـ اقتر اح بر امج تعليمية لمعالجة الضعف أو الصعوبات في مهار ات الكتابة . ـ در اسة مهار ات الكتابة لدى ذوي الاحتياجات الخاصة وصعوباتها و اقتر اح بر امج تعليمية و علاجية مناسبة. 
أحميدة، فتحي محمود الكريم (2009). أثر أنثطة الكتابة اليومية في تطوير الكتابة المبكرة لدى أطفال الروضة، مجلة كلية التربية، العدد 29. جامعة الإمارات العمبدة العربية المتحدة.

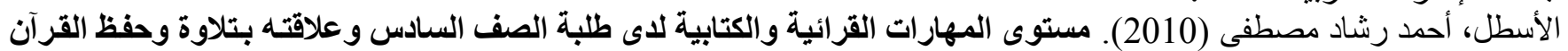

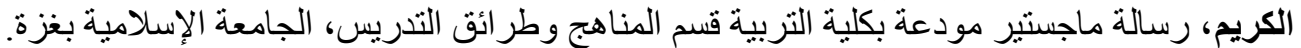

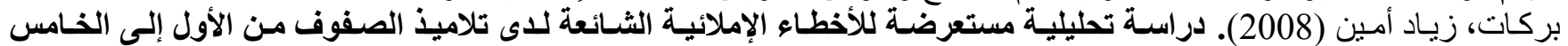

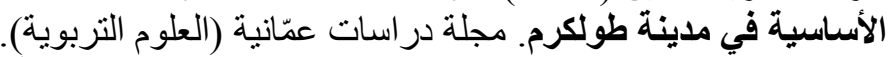

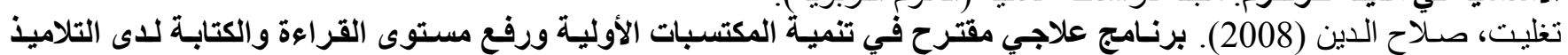

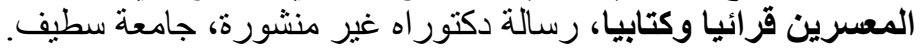

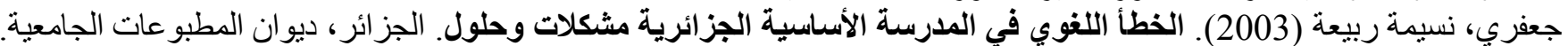

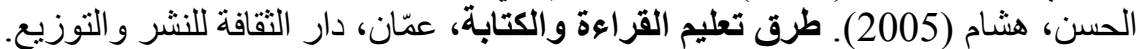

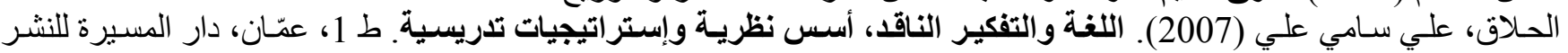
و التوزيع و الطباعة. الخويسكي، زين كامل (2008). المهارات اللغوية (الاستماع، التحدث، القراعة،، الكتابة) وعوامل تنمية المهارات اللغوية عند العرب، الإسكندرية، دار المعرفة الجامعية. الدليمي، طه علي حسين و اللو ائلي، سعاد عبد الكية، الكريم عباس (2005). اللغة العربية مناهجها وطرائق تدريسها. ط 1، عمّان، دار الثروق للنشر و التوزيع.

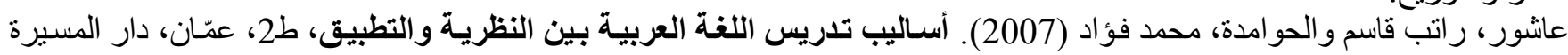
للنشر والتوزيع و الطباعة.

عبد الباري، ماهر شعبان (2010). المهارات الكتابية من النشأة إلى التدريس، ط 1، عمّان، دار المسيرة للنشر و التوزيع والطباعة.

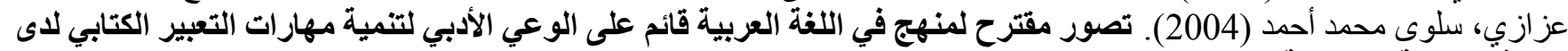

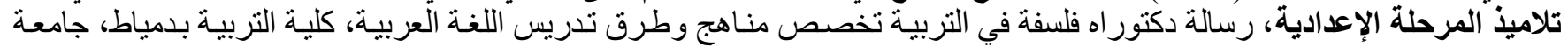

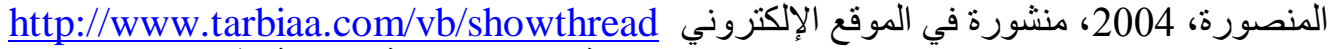

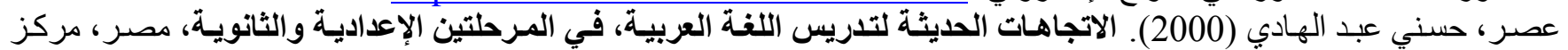
الإسكندرية للكتاب.

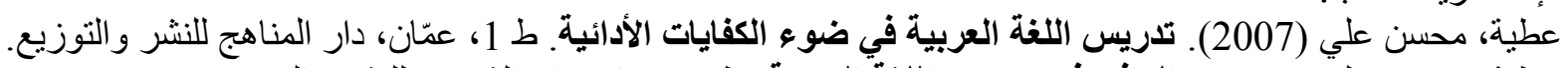

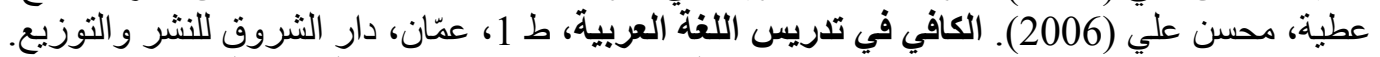

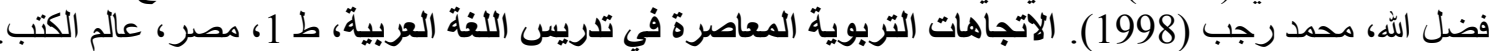

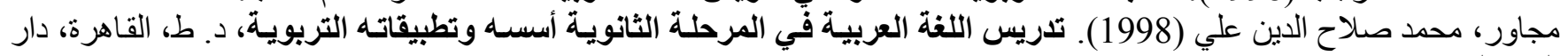
الفكر العربي. مدكور، علي أحمد (2000). تدريس فنون اللفة العربية، القاهرة، دار الفكر العربي.

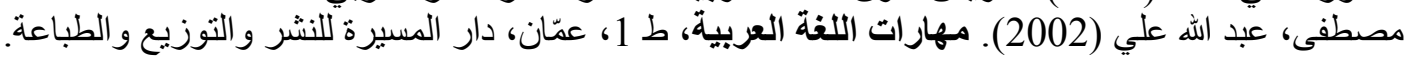

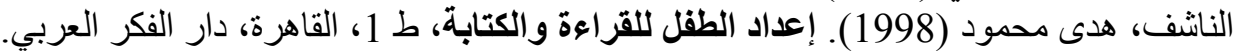

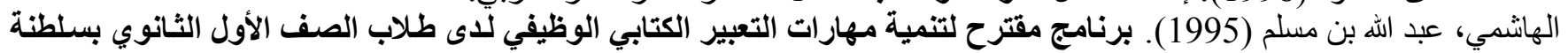

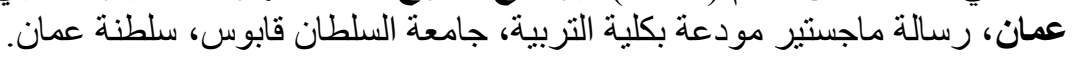

Frederique brin et al(1997).Dictionnaire d'orthophonie ,l'Ortho édition, Franc

Toulon-page ,chantal(). La rééducation de l'écriture de l'enfant ( pratique de la graphothérapie ), Masson, Paris.

Silamy ,norber( 1999). Dictionnaire de psychologie, Larousse, Canada.

Abdul-Khafaji, Adnan(2021). Common mistakes in drawing writing for students of Arabic of nonnative speakers ,Arid International Journal of Educational and Psychological Sciences ,VOL.2 NO.4, July(pp. 56-80). 